\title{
Isolation of a 1,4-diketone intermediate in oxidative dimerization of 2-hydroxyanthracene and its conversion to oxahelicene $\dagger$
}

Cite this: Chem. Commun., 2015 51,4607

Received 27th January 2015, Accepted 9th February 2015

DOI: $10.1039 / c 5 c c 00764 j$

www.rsc.org/chemcomm
Takashi Matsuno, ${ }^{a}$ Yutaro Koyama, ${ }^{a}$ Satoru Hiroto, ${ }^{* a}$ Jatish Kumar, ${ }^{b}$ Tsuyoshi Kawai ${ }^{b}$ and Hiroshi Shinokubo*a

\begin{abstract}
Oxidation of 2-hydroxy-9,10-dialkynylanthracenes resulted in highly regioselective dimerization to furnish metastable dearomatized 1,4-diketones rather than stable aromatic diols. The 1,4-diketones were converted to oxahelicenes, which exhibited strong fluorescence both in solution and solid state as well as chiroptical properties.
\end{abstract}

2,2'-Dihydroxy-1,1'-binaphthyl (BINOL) is one of the most versatile chiral scaffolds in asymmetric synthesis, which is frequently employed to create a variety of metal and non-metal chiral catalysts. Oxidative coupling of 2-naphthol and other derivatives has been a useful methodology to provide BINOL and other axially chiral aromatic diols. The mechanism of oxidative coupling has been considered in the following three processes: (i) homolytic coupling of two radicals $\left(\mathrm{A}^{\bullet}+\mathrm{A}^{\bullet}\right)$, (ii) heterolytic coupling $\left(\mathrm{A}^{+}+\mathrm{A}\right)$ and (iii) radical-anion coupling $\left(\mathrm{A}^{\bullet}+\mathrm{A}^{-}\right) \cdot{ }^{1-3}$ In the radical-radical coupling process, formation of a diketone intermediate is expected through dimerization of a carbon-centred radical contributor of the 2-naphthoxyl radical (Scheme 1). However, such a dearomatized 1,4-diketone has been an elusive intermediate due to its instability. The 1,4-diketone rapidly undergoes tautomerization to the more stable enol form to yield BINOL.

During the course of our study on oxidation of aromatic alcohols, ${ }^{4}$ we unexpectedly isolated such metastable 1,4-diketone intermediates 2 by oxidation of 2-hydroxyanthracenes 1 . Although oxidative dimerization of 2-hydroxyanthracenes to BINOL-like axially chiral diols has been reported, dearomatized 1,4-diketone species have never been isolated. ${ }^{5}$ We have also demonstrated the synthesis of oxahelicenes 6 from 1,4-diketones 2, which exhibit

\footnotetext{
${ }^{a}$ Department of Applied Chemistry, Graduate School of Engineering, Nagoya University, Chikusa-ku, Nagoya 464-8603, Japan.

E-mail: hshino@apchem.nagoya-u.ac.jp, hiroto@apchem.nagoya-u.ac.jp

${ }^{b}$ Graduate School of Material Science, Nara Institute of Science and Technology (NAIST), Ikoma, 630-0192, Japan

$\dagger$ Electronic supplementary information (ESI) available: Experimental procedures, spectral data for all new compounds, photophysical data and crystallographic data of $2 \mathbf{b}, \mathbf{4}, \mathbf{5 b}, \mathbf{6 b}$ and 6-(P). CCDC 1041270-1041274. For ESI and crystallographic data in CIF or other electronic format see DOI: 10.1039/ c5cc00764j
}
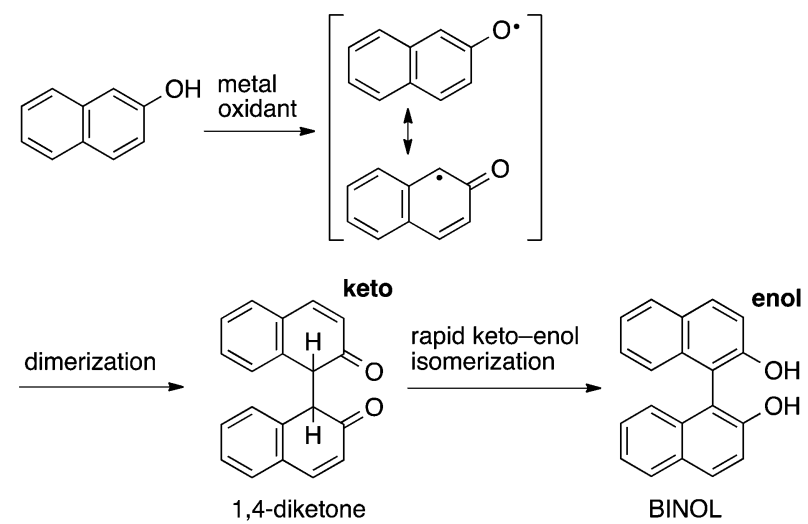

Scheme 1 Plausible reaction mechanism of BINOL formation via the radical-radical coupling process.

bright fluorescence both in solution and solid state as well as chiroptical properties.

We found that oxidation of 2-hydroxy-9,10-bis(triethylsilylethynyl)anthracene 1a with $\mathrm{MnO}_{2}$ in dichloromethane at room temperature afforded dimeric diketone $2 \mathbf{a}$ in $63 \%$ yield without formation of diol 4 (Scheme 2). The structure of $2 \mathrm{a}$ was assigned on the basis of NMR and MS analyses. The ${ }^{1} \mathrm{H}$ NMR spectrum of 1a exhibited olefinic signals at 8.17 and $6.35 \mathrm{ppm}$ as well as a methine proton signal at $4.35 \mathrm{ppm}$. The presence of carbonyl groups was confirmed by the peak at $200.9 \mathrm{ppm}$, as shown in its ${ }^{13} \mathrm{C}$ NMR spectrum. Triisopropylsilyl (TIPS) substituted diketone $\mathbf{2 b}$ was similarly prepared in $50 \%$ yield. In this case, ortho-quinone $\mathbf{3} \mathbf{b}$ was obtained as a byproduct. The dimerization also proceeded with less bulky tert-butyl substituent 1c to provide $2 \mathrm{c}$ in $84 \%$ yield. The improvement of the yield is probably due to steric reason. Diketones 2 were relatively stable but treatment with $\mathrm{KO}^{t} \mathrm{Bu}$ resulted in tautomerization to afford the more stable enol-form 4 in 59\% yield (Scheme 2).

The structures of $\mathbf{2 b}$ and $\mathbf{4}$ were unambiguously elucidated by X-ray diffraction analysis (Fig. 1). In the case of $\mathbf{2 b}$, two anthracene rings overlap in a face-to-face fashion. Notably, the bond length of the bridging carbon-carbon linkage is $1.62 \AA$, 

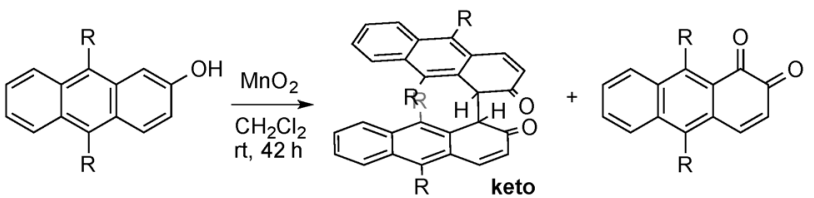

1a: $\mathrm{R}=\bar{\equiv} \mathrm{SiEt}_{3}$
1b: $\mathrm{SiPr}_{3}$
1c: $\bar{\equiv}{ }_{\mathrm{Bu}}$
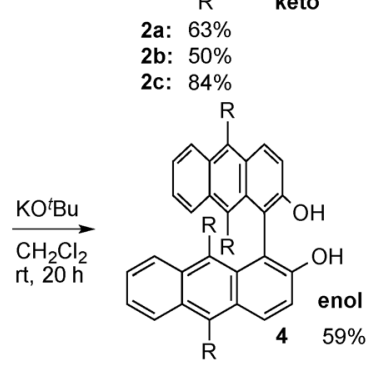

3a: N.D.

3c: N.D.

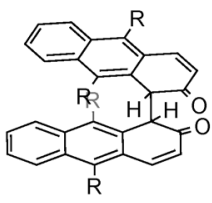

$2 b$
Scheme 2 Oxidation of 2-hydroxyanthracenes 1.

which is considerably longer than that of the standard $\mathrm{C}_{\mathrm{sp}^{3}}-\mathrm{C}_{\mathrm{sp}^{3}}$ bond (1.54 $\AA$ ). This elongation is caused by columbic repulsion between two anthracene rings. This could be a reason for facile bond cleavage of $\mathbf{2 b}$ to $\mathbf{1 b}$ during silica-gel column chromatography. In the case of $\mathbf{4}$, two anthracene units cross each other at an angle of $102.7^{\circ}$, which is larger than that of BINOL. ${ }^{6}$ The alkynyl groups are substantially bent due to the steric repulsion with anthracene moieties.

The isolation of the keto-form 2 was intriguing because BINOL derivatives usually exhibit no keto-enol tautomerism due to the instability of keto-forms. ${ }^{7}$ The distorted structure of 4 should be a clue for the relative stabilization of the keto-form 2 because no keto-enol tautomerization could be observed for
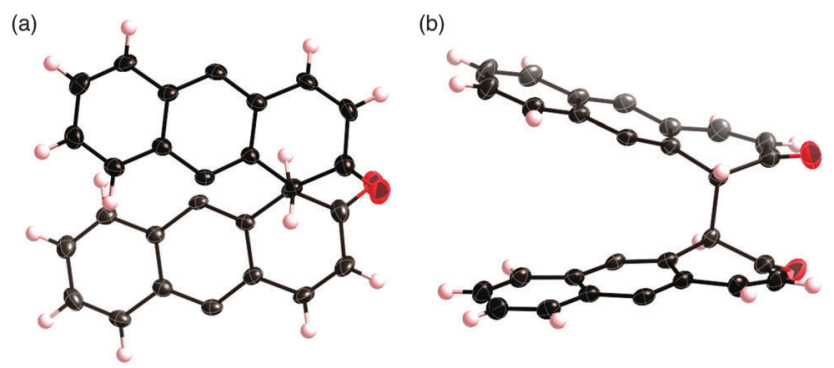

(c)

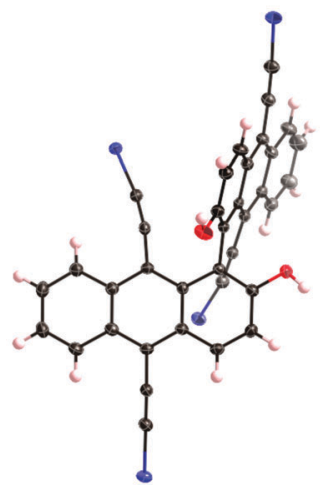

(d)

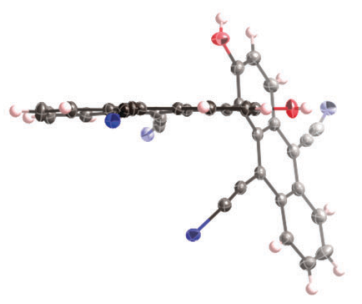

Fig. 1 X-ray crystal structures of $\mathbf{2} \mathbf{b}$ and $\mathbf{4}$. (a) Top view and (b) side view of $\mathbf{2 b}$ and (c) side view and (d) front view of $\mathbf{4}$. The ethynyl groups are omitted in (a) and (b), and 'Pr groups are omitted in (c) and (d) for clarity. The thermal ellipsoids are scaled at the 50\% probability level. the corresponding monomer $\mathbf{1}$. The large displacement of conformations between $\mathbf{2 b}$ and $\mathbf{4}$ should increase the conversion barrier from $\mathbf{2 b}$ to $\mathbf{4}$, which is one of the key factors for the stability of $\mathbf{2 b}$. Moreover, the calculated LUMO of $\mathbf{2 b}$ spread over the entire molecule, indicating effective delocalization of $\pi$-electrons (Fig. S32, ESI $\dagger$ ). This is also suggested by optical analysis. In comparison to 1,1-dimethoxy-2-oxoanthracene, a slight but obvious red-shift of the lowest energy band was observed for 2b (Fig. S28, ESI $\dagger$ ), indicating the presence of electronic communication between two anthracene units in $\mathbf{2 b}$. This interaction between anthracenes would also contribute to the stabilization of the keto-form $2 \mathbf{b}$.

We then attempted construction of the fused furan ring to obtain oxahelicenes 6. $^{8}$ Helical-shaped $\pi$-conjugated molecules have attracted tremendous interest as promising candidates for new-age functional materials. ${ }^{9,10}$ Their rigid and twisted $\pi$-condensed ring systems induce chiroptical properties such as enhanced CD signals and circularly polarized luminescence (CPL) ${ }^{11}$ They, however, commonly have low emission efficiency due to their ortho-condensed structures, which result in rapid intersystem crossing from an excited singlet state to a triplet state. ${ }^{12}$

We found that treatment of $2 \mathrm{a}$ with $\mathrm{TsOH} \cdot \mathrm{H}_{2} \mathrm{O}$ and methyl orthoformate in methanol yielded 57\% of diacetal 5a. Methoxy groups were readily eliminated by treatment with $\mathrm{CF}_{3} \mathrm{SO}_{3} \mathrm{H}$ to furnish oxahelicene $\mathbf{6 a}$ in $16 \%$ yield (Scheme 3 ). In the case of TIPS derivative $2 \mathbf{b}$, the yield of $\mathbf{6 b}$ was improved to $47 \%$ due to the higher stability of the alkyne group under acidic conditions. Unfortunately, the corresponding cyclic diacetal $\mathbf{5}$ was not obtained from $2 c$.

The structures of $\mathbf{5 b}$ and $\mathbf{6 b}$ were confirmed by X-ray diffraction analysis (Fig. 2). The X-ray crystal structure revealed a distorted helical conformation of $\mathbf{6 b}$. As shown, two anthracene units and two ethynyl groups are bent due to severe steric repulsion. The dihedral angle between the two naphthalene rings is $40.9^{\circ}$.

Fig. 3 displays UV/vis absorption spectra of $\mathbf{1 b}, \mathbf{4}, \mathbf{6 a}$ and $\mathbf{6 b}$ and fluorescence spectra of $\mathbf{6 a}$ and $\mathbf{6 b}$ in dichloromethane solutions. The dimer 4 exhibited a bathochromic shift compared to $\mathbf{1 b}$ as commonly seen in perpendicularly linked acene dimers. ${ }^{13} \mathrm{~A}$ larger shift was observed for $\mathbf{6 b}$, indicating effective $\pi$-conjugation over two anthracene units. No significant difference between $\mathbf{6 a}$ and 6b was observed. On the other hand, emission spectra exhibited clear differences. The emission of $6 \mathbf{a}$ appeared at $558 \mathrm{~nm}$ with $\Phi_{\mathrm{f}}=0.45$. Slight blue-shifted and enhanced emission $\left(\Phi_{\mathrm{f}}=0.66\right)$

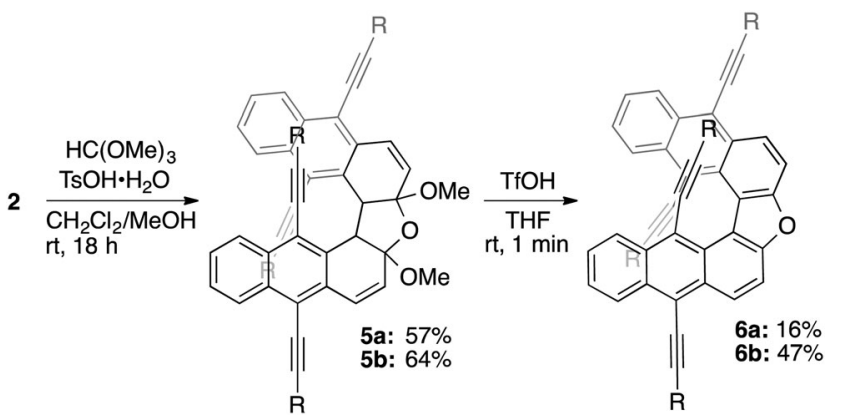

Scheme 3 Conversion of $\mathbf{2}$ to oxahelicenes 6 . 
(a)
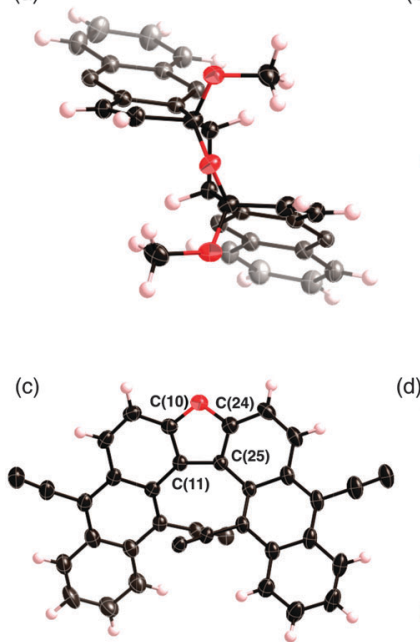

(b)

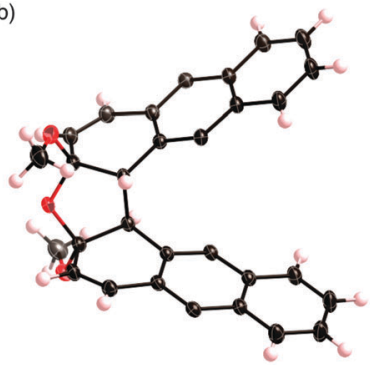

(d)

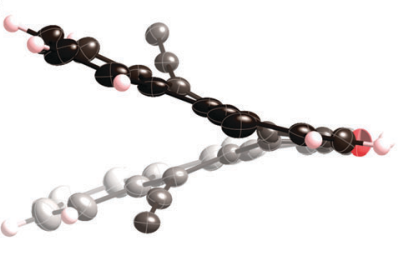

Fig. 2 X-ray crystal structures of $\mathbf{5 b}$ and $\mathbf{6 b}$ : (a) top view and (b) side view of $\mathbf{5 b}$; (c) top view and (d) side view of $\mathbf{6} \mathbf{b}$. The silylethynyl groups in (a) and (b) and triisopropylsilyl groups in (c) and (d) are omitted for clarity. The thermal ellipsoids are scaled at the $50 \%$ probability level.

was observed for $\mathbf{6 b}$. This difference can be accounted for by the higher flexibility of $\mathbf{6 a}$, enhancing non-radiative decay, judging from the larger Stokes shift of $6 \mathbf{a}\left(\Delta \nu=1803 \mathrm{~cm}^{-1}\right)$. These results indicate that the substituent can control the emission feature of helicene derivatives.

The chiroptical properties of $\mathbf{6 b}$ were also investigated. Optical resolution was accomplished by HPLC using a CHIRALPAK ${ }^{\circledR}$ IF column. Both enantiomers were stable enough and underwent no racemization at room temperature. The $\mathrm{CD}$ spectrum of the first eluted fraction exhibited a $(+)$ Cotton effect and that of the other isomer exhibited a (-) Cotton effect as the mirror image (Fig. 4). The absolute structure of the latter enantiomer was proven to be a $(P)$-helix on the basis of X-ray diffraction analysis (Fig. S30, ESI $\dagger$ ) and TD-DFT calculations. Furthermore, both enantiomers exhibited CPL with $g_{\text {lum }}=1.2 \times 10^{-3}$. This value is consistent with heterohelicenes and relatively high for small organic molecules.

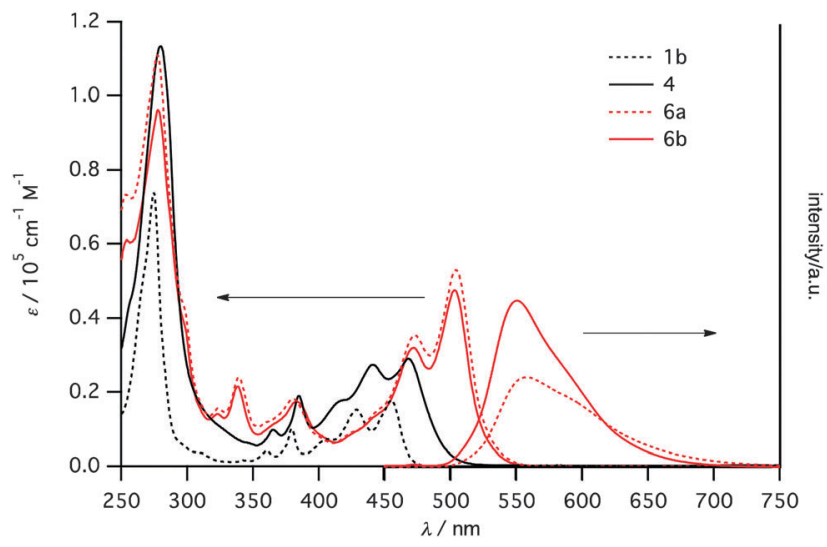

Fig. 3 UV/vis absorption spectra of $\mathbf{1 b}$ (black, dotted), 4 (black, solid) $\mathbf{6 a}$ (red dotted) and $\mathbf{6 b}$ (red solid), and emission spectra of $\mathbf{6 a}$ (red, dotted) and $\mathbf{6 b}$ (red, solid). All spectra were recorded in dichloromethane.

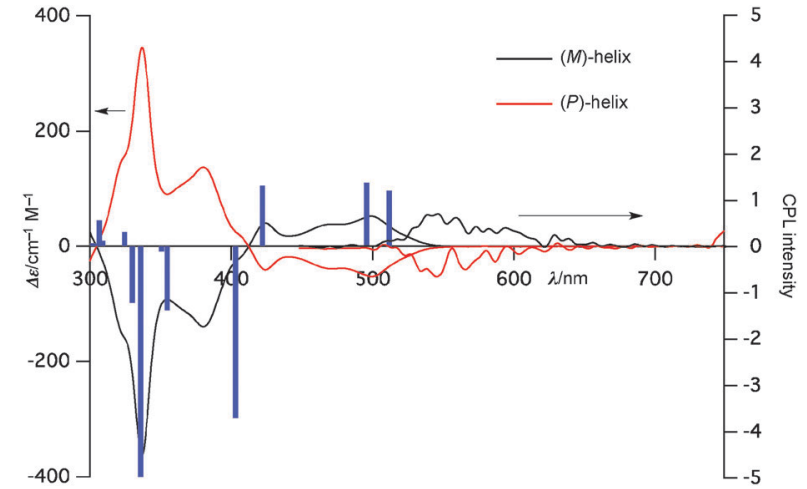

Fig. $4 \mathrm{CD}$ and $\mathrm{CPL}$ spectra of $\mathbf{6 b}$. Blue bars represent oscillator strengths for the (M)-helix enantiomer estimated by the TD-DFT method. All spectra were recorded in dichloromethane solution $\left(c=1.0 \times 10^{-5} \mathrm{M}\right)$.

Interestingly, oxahelicene $\mathbf{6 b}$ exhibited intense emission in the solid state (Fig. 5). A racemic microcrystalline sample of $\mathbf{6 b}$ showed strong fluorescence $\left(\Phi_{\mathrm{f}}=0.41\right)$. This fluorescence quantum yield in the solid state is the highest among helicene derivatives reported previously. ${ }^{14}$ The emission was reduced for enantiomerically pure crystals of $6-(P)\left(\Phi_{\mathrm{f}}=0.14\right)$. Reduction in the quantum yield was due to differences in the crystal packing between racemic $\mathbf{6 b}$ and its $(P)$-isomer $\mathbf{6}-(\boldsymbol{P})$, suggested by the red-shifted spectrum of $6-(P)\left(\lambda_{\mathrm{em}}=581 \mathrm{~nm}\right)$ as compared with $\mathbf{6 b}\left(\lambda_{\mathrm{em}}=574 \mathrm{~nm}\right)$. In the crystal packing of $\mathbf{6 b}$, a pair of $(P)$ - and $(M)$-enantiomers are placed in a face-to-face fashion to form a coplanar dimer (Fig. S31, ESI $\dagger$ ). In contrast, molecules in 6-(P) are aligned in a herringbone fashion.

In summary, we have discovered that oxidation of 2-hydroxyanthracenes furnished dearomatized diketones 2 as metastable intermediates. Treatment of $\mathbf{2 b}$ with a base or heating induced tautomerization into bianthranyl diol 4 . We have also achieved synthesis of oxahelicenes 6 from 2 in two steps under mild conditions. Oxahelicene $\mathbf{6 b}$ exhibited strong emission and CPL activity. This work demonstrates that oxidation of hydroxylated oligoacenes offers an easy access to distorted $\pi$-conjugated molecules with fascinating structures and optical characteristics.

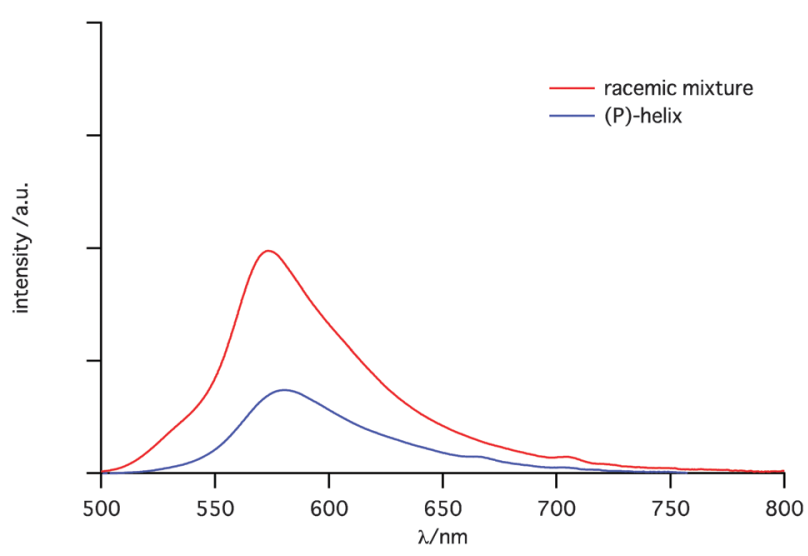

Fig. 5 Emission spectra of a racemic mixture (red) and a $(P)$-enantiomer (blue) of $\mathbf{6 b}$ in the solid state (microcrystals). 
This work was supported by Grants-in-Aid for Scientific Research on Innovative Areas "Science of Atomic Layers" (26107519) and "pi-System Figuration” (26102003) and Program for Leading Graduate Schools "Integrative Graduate Education and Research in Green Natural Sciences”, MEXT, Japan. H.S. acknowledges the financial support from Yamada Science Foundation.

\section{Notes and references}

1 (a) Q.-X. Guo, Z.-J. Wu, Z.-B. Luo, Q.-Z. Liu, J.-L. Ye, S.-W. Luo, L.-F. Cun and L.-Z. Gong, J. Am. Chem. Soc., 2007, 129, 13927; (b) M. Matsushita, K. Kamata, K. Yamaguchi and N. Mizuno, J. Am. Chem. Soc., 2005, 127, 6632; (c) X. Li, J. B. Hewgley, C. A. Mulrooney, J. Yang and M. C. Kozlowski, J. Org. Chem., 2003, 68, 5500.

2 M. Hovorka and J. Závada, Tetrahedron, 1992, 48, 9517.

3 (a) H. Egami, K. Matsumono, T. Oguma, T. Kunisu and T. Katsuki, J. Am. Chem. Soc., 2010, 132, 13633; (b) M. Smrčina, Š. Vyskočil, B. Máca, M. Polásek, T. A. Claxton, A. P. Abbott and P. Kočovský, J. Org. Chem., 1994, 59, 2156.

4 Y. Koyama, S. Hiroto and H. Shinokubo, Angew. Chem., Int. Ed., 2013, 52, 5740.

5 (a) S. Zhang, Y. Wang, Z. Song, K. Nakajima and T. Takahashi, Chem. Lett., 2013, 42, 697; (b) S. Takizawa, J. Kodera, Y. Yoshida, M. Sako, S. Breukers, D. Enders and H. Sasai, Tetrahedron, 2014, 70, 1786.

6 BINOL has a cisoid conformation (dihedral angle $<90^{\circ}$ ) in crystal. (a) K. Mori, Y. Masuda and S. Kashino, Acta Crystallogr., Sect. C: Cryst. Struct. Commun., 1993, 49, 1224; (b) L. Pu, Chem. Rev., 1998, 98, 2405.

7 Keto-enol tautomerism of 1,4-naphthalenediols was extensively investigated. (a) E. P. Kündig, A. E. García, T. Lomberget and G. Bernardinelli, Angew. Chem., Int. Ed., 2006, 45, 98; (b) H. Laatsch, Liebigs Ann. Chem., 1980,$140 ;(c)$ M. S. Pearson, B. J. Jensky, F. X. Greer, J. P. Hagstrom and N. M. Wells, J. Org. Chem., 1978, 43, 4617. However, no keto tautomer of monohydroxyarenes has been isolated.
8 (a) R. Irie, A. Tanoue, S. Urakawa, T. Imahori, K. Igawa, T. Matsunoto, K. Tomooka, S. Kikuta, T. Uchida and T. Katsuki, Chem. Lett., 2011, 40, 1343; (b) M. Salim, A. Akutsu, T. Kimura, M. Minabe and M. Karikomi, Tetrahedron Lett., 2011, 52, 4518; (c) J. F. Schneider, M. Nieger, K. Nättinen and K. H. Dötz, Synthesis, 2005, 1109.

9 For reviews, see: $(a)$ N. Saleh, C. Shen and J. Crassous, Chem. Sci., 2014, 5, 3680; (b) M. Gingras, Chem. Soc. Rev., 2013, 42, 968; (c) Z. Peng and N. Takenaka, Chem. Rec., 2013, 13, 28; (d) Y. Shen and C.-F. Chen, Chem. Rev., 2012, 112, 1463; (e) R. Amemiya and M. Yamaguchi, Chem. Rec., 2008, 8, 116; $(f)$ A. Rajca and M. Miyasaka, in Functional Organic Materials: Syntheses, Strategies, and Applications, ed. T. J. J. Müller and U. H. F. Bunz, Wiley-VCH, Weinheim, 2007, p. 543; $(g)$ C. Nuckolls, R. Shao, W.-G. Jang, N. A. Clark, D. M. Walba and T. J. Katz, Chem. Mater., 2002, 14, 773; (h) T. J. Katz, Angew. Chem., Int. Ed., 2000, 39, 1921.

10 For recent edge-cutting reports on helicene-like molecules, see: (a) D. Schweinfurth, M. Zalibera, M. Kathan, C. Shen, M. Mazzolini, N. Trapp, J. Crassous, G. Gescheidt and F. Diederich, J. Am. Chem. Soc., 2014, 136, 13045; (b) Y. Kimura, N. Fukawa, Y. Miyauchi, K. Noguchi and K. Tanaka, Angew. Chem., Int. Ed., 2014, 53, 8480; (c) L. Pospíšil, L. Bednárová, P. Štépánek, P. Slavíček, J. Vávra, M. Hromadvá, H. Dlouhá, J. Tarábek and F. Teplý, J. Am. Chem. Soc., 2014, 136, 10826; (d) D. Mendola, N. Saleh, N. Vanthuyne, C. Roussel, L. Toupet, F. Castiglione, T. Caronna, A. Mele and J. Crassous, Angew. Chem., Int. Ed., 2014, 53, 5786; (e) C. Shen, E. Anger, M. Srebro, N. Vanthuyne, K. K. Deol, T. D. Jefferson, G. Muller, J. A. G. Williams, L. Toupet, C. Roussel, J. Autschbach, R. Réau and J. Crassous, Chem. Sci., 2014, 5, 1915.

11 K. Nakamura, S. Furumi, M. Takeuchi, T. Shibuya and K. Tanaka, J. Am. Chem. Soc., 2014, 136, 5555 and references are therein.

12 D. Beljonne, Z. Shuai, G. Pourtois and J. L. Bredas, J. Phys. Chem. A, 2001, 105, 3899.

13 K. Tanaka, N. Aratani, D. Kuzuhara, S. Sakamoto, T. Okujima, N. Ono, H. Uno and H. Yamada, RSC Adv., 2013, 3, 15310.

14 H. Oyama, K. Nakano, T. Harada, R. Kuroda, M. Naito, K. Nobusawa and K. Nozaki, Org. Lett., 2013, 15, 2104. 